\title{
Use of Ferric Chloride and Chitosan as Coagulant to Remove Turbidity and Color from Landfill Leachate
}

\author{
Siti Fatihah Ramli ${ }^{1, a}$, Hamidi Abd Aziz ${ }^{2, b^{*}}$ \\ ${ }^{1}$ School of Civil Engineering, Universiti Sains Malaysia (USM), 14300 Nibong Tebal, Penang, \\ Malaysia \\ ${ }^{2}$ School of Civil Engineering, Universiti Sains Malaysia (USM), 14300 Nibong Tebal, Penang, \\ Malaysia

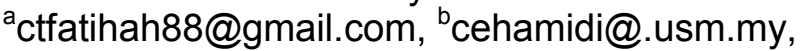

Keywords: Ferric chloride, Chitosan, Color, Turbidity

\begin{abstract}
Coagulation and flocculation are two of the most common chemical treatment methods used in leachate treatment. Existing coagulants are mainly based on $\mathrm{Al}$ and Fe salts. The use of nonchemical based coagulants, especially natural polymers, in leachate treatment has not been thoroughly investigated. Natural coagulants have less harmful effects to human health compared with metal salts. This study aimed to investigate the effectiveness of ferric chloride $\left(\mathrm{FeCl}_{3}\right)$ and chitosan as coagulant in removing the turbidity and color from landfill leachate. Leachate was collected from the Matang Landfill site located at Taiping, Perak, Malaysia. When used as the main coagulant in this study, $\mathrm{FeCl}_{3}$ was able to remove $97.78 \%$ of the turbidity and $95.54 \%$ of the color of the leachate at an optimum dosage of $3600 \mathrm{mg} / \mathrm{L}$. At a dosage of $60 \mathrm{mg} / \mathrm{L}$, chitosan only removed $23.52 \%$ of the turbidity and $14.67 \%$ of the color at $\mathrm{pH}$ levels of 9 and 4 , respectively. The optimum $\mathrm{pH}$ value for $\mathrm{FeCl}_{3}$ was 6 . Therefore, $\mathrm{FeCl} 3$ is an effective coagulant that can help to remove the colour and turbidity compared to chitosan.
\end{abstract}

\section{Introduction}

Landfill leachate is defined as any polluted liquid effluent that moves through deposited waste and discharged within a landfill or dump site by external sources [1]. Landfill leachate could be a potential source of surface and ground water contamination if it is not treated and safely disposed. This risk arises from the fact that contaminants may percolate in soils and subsoils and in turn pollute the receiving water [2].

Wastewater is generally treated through the coagulation-flocculation process followed by sedimentation and filtration [3]. Coagulation can also be performed to remove heavy metals and non-biodegradable organic compounds in leachate [2].

Chemicals are added to water to destabilize particle suspension and to produce flocculent particles. These particles are then settled and drained from water to become coagulants. Coagulants can be classified into several types, including simple metal salts, prehydrolyzed metal salts, polyelectrolytes, and coagulant aids. An example of a metal salt is ferric chloride $\left(\mathrm{FeCl}_{3}\right) . \mathrm{FeCl}_{3}$ is commonly in liquid form, but it can also come in crystal or anhydrous forms [4].

Polyelectrolytes are polymers that comprise certain functional groups and an ionizable polymer backbone. Polyelectrolytes have several types, such as activated silica, synthetic polymer, and natural polyelectrolytes [4].

Natural polyelectrolytes can be extracted from plants or animals. They can be used as substitutes for synthethic polyelectrolytes. Moreover, natural polyelectrolytes are easily available, cost-effective, biodegradable, and safe for human health [5]. Chitosan is obtained through chitin deacetylation and is readily soluble in acidic solutions. Apart from being a biodegradable and nontoxic polyelectrolyte, chitosan is a linear cationic polymer with high molecular weight [6]. Chitosan also has more advantages compared with other chemical coagulants. Some of these advantages are high COD removal efficiency, zero pollutants, and easy sludge treatment [7]. 


\section{Experimental Procedures}

The leachate samples were collected from the Matang Landfill site located at Perak, Malaysia. The samples were collected and preserved according to the Standard Methods for the Examination of Water and Wastewater (APHA, 2005) [8]. The $\mathrm{FeCl}_{3}$ solution was prepared based on the method presented in [9]. $\mathrm{FeCl}_{3} \cdot 6 \mathrm{H}_{2} \mathrm{O}$ was dissolved in distilled water and freshly prepared to avoid aging. The solution was then kept in cold storage at $4{ }^{\circ} \mathrm{C}$. The chitosan powder was obtained from ChitoChem (Malaysia). A total of $100 \mathrm{mg}$ of chitosan powder was weighed and then mixed with $10 \mathrm{~mL}$ of $0.1 \mathrm{M} \mathrm{HCL}$ in a beaker. The solution was set aside for about $1 \mathrm{~h}$ to dissolve. Then, the mixture was diluted in $100 \mathrm{~mL}$ of distilled water. This solution was prepared daily as needed [10].

The coagulation test was performed using jar test equipment (SW6 Stuart Bibby Scientific Limited, UK). The leachate sample was kept in ambient temperature and then thoroughly shaken to avoid solid materials from settling. The $\mathrm{pH}$ of the sample was adjusted using $3 \mathrm{M} \mathrm{NaOH}$ and $3 \mathrm{M}$ $\mathrm{HCl}$. The study involved rapid mixing, slow mixing, and sedimentation in a batch process. Then, $500 \mathrm{~mL}$ of leachate samples was poured into six beakers, which were then simultaneously agitated. The rotational speed varied accordingly to allow the simulation of different mixing intensities and resulting flocculation process [11].

\section{Results and Discussion}

Influence of Coagulant Dosage on Coagulation using Ferric Chloride and Chitosan. Coagulant dosage is one of the most important parameters that must be considered in the coagulation and flocculation process. Insufficient dosage or overdosing results in the poor performance of the coagulant in flocculation. Therefore, optimum coagulant dosage must be determined to minimize dosing cost and achieve optimum removal rates [6].

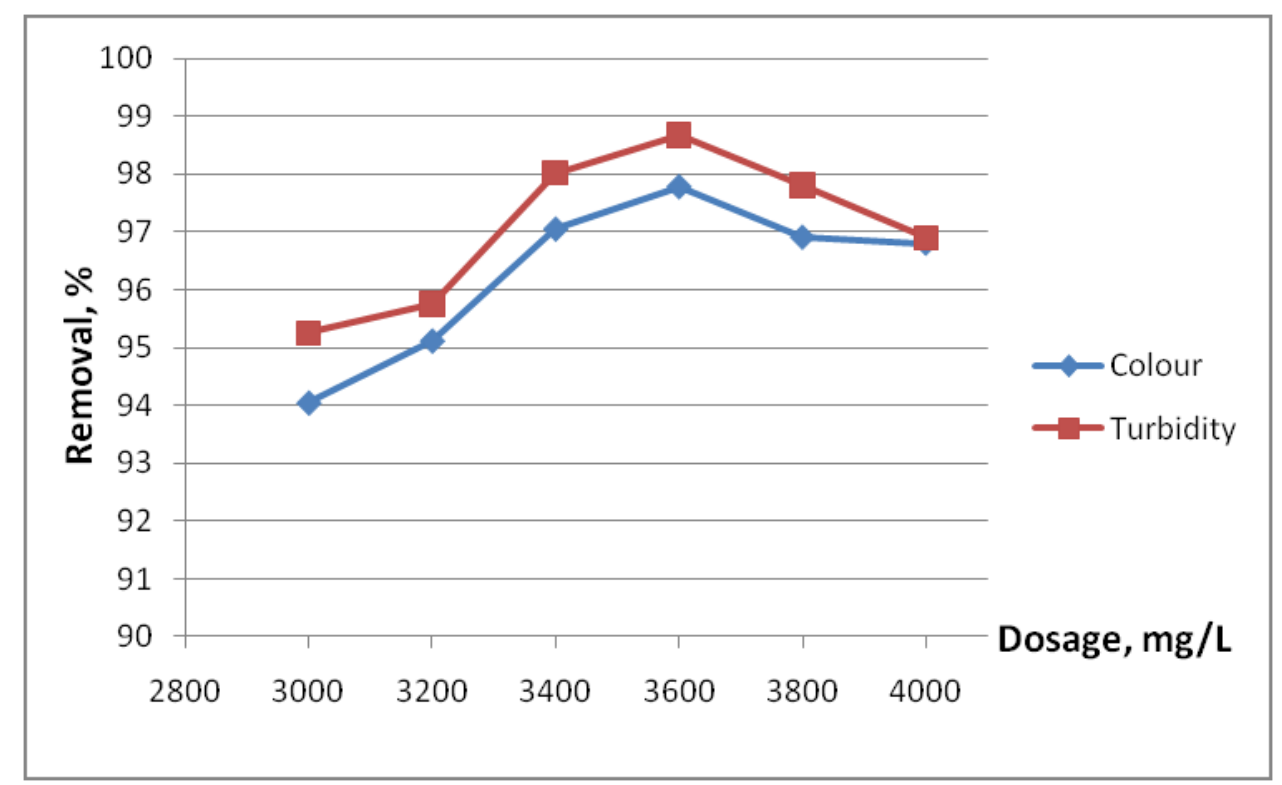

Fig. 1. Effects of Coagulant Dosage on Color and Turbidity Removal using $\mathrm{FeCl}_{3}$ 


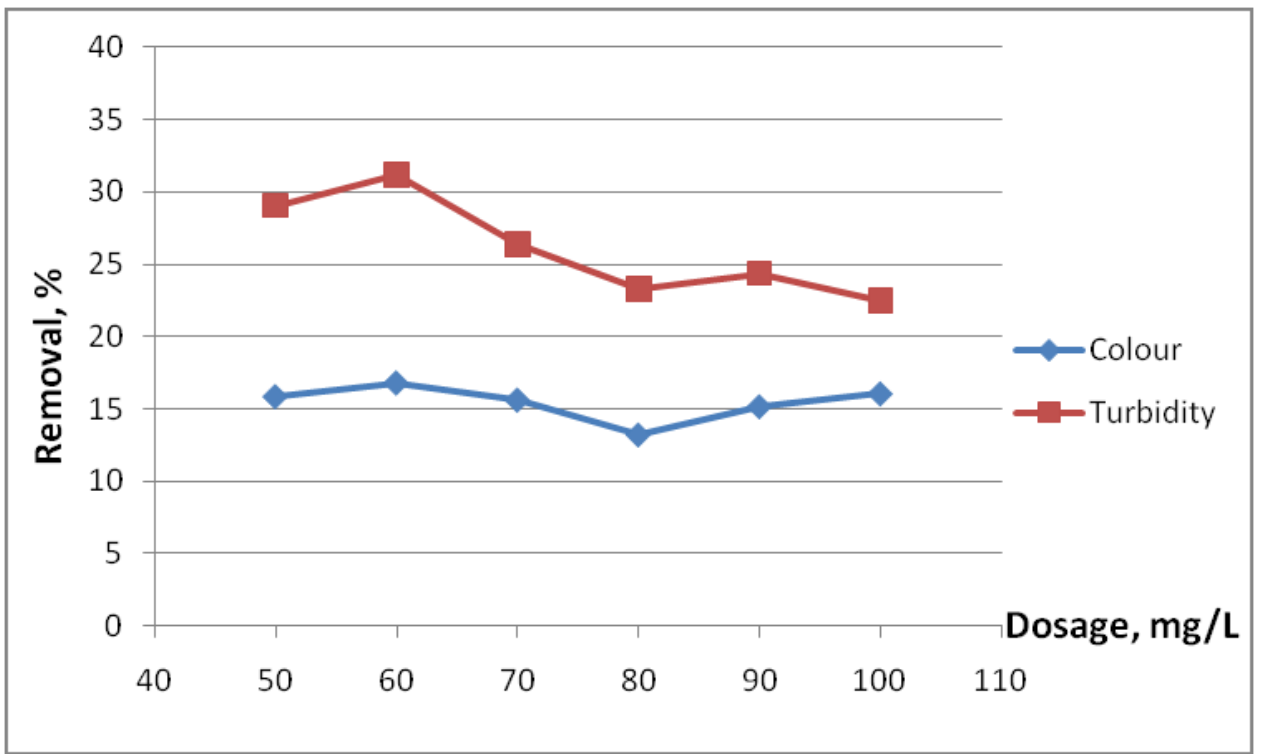

Fig. 2. Effects of Coagulant Dosage on Color and Turbidity Removal using Chitosan

The effects of coagulant dosage on color and turbidity removal using $\mathrm{FeCl}_{3}$ and chitosan are plotted in Figs. 1 and 2, respectively. The tests were conducted by changing the coagulant dosage at a constant $\mathrm{pH}$ value. The dosages of $\mathrm{FeCl}_{3}$ varied from $3000 \mathrm{mg} / \mathrm{L}$ to $4000 \mathrm{mg} / \mathrm{L}$ at a constant $\mathrm{pH}$ of 6. Meanwhile, the dosages of chitosan varied from $50 \mathrm{mg} / \mathrm{L}$ to $100 \mathrm{mg} / \mathrm{L}$ at a constant $\mathrm{pH}$ of 4 . As the $\mathrm{FeCl}_{3}$ dosage increased from $3000 \mathrm{mg} / \mathrm{L}$ to $3600 \mathrm{mg} / \mathrm{L}$, the removal rates of color and turbidity also increased. However, the removal rates of color and turbidity decreased when $\mathrm{FeCl}_{3}$ increased to $4000 \mathrm{mg} / \mathrm{L}$. Therefore, the optimum $\mathrm{FeCl}_{3}$ dosage was $3600 \mathrm{mg} / \mathrm{L}$. The highest percentage of color and turbidity removal was reached at a $\mathrm{FeCl}_{3}$ dosage of $3600 \mathrm{mg} / \mathrm{L}$; the removal rates were $97.77 \%$ and $98.68 \%$, respectively. The same pattern was observed in the color and turbidity removal using chitosan. As chitosan dosage increased from $50 \mathrm{mg} / \mathrm{L}$ to $60 \mathrm{mg} / \mathrm{L}$, the removal rates of color and turbidity also increased. However, the removal rates of both color and turbidity decreased when chitosan dosage increased from $60 \mathrm{mg} / \mathrm{L}$ to $100 \mathrm{mg} / \mathrm{L}$. Therefore, the optimum chitosan dosage was $60 \mathrm{mg} / \mathrm{L}$. The highest percentage of color and turbidity removal was achieved at a chitosan dosage of $60 \mathrm{mg} / \mathrm{L}$; the removal rates were $31.17 \%$ and $16.8 \%$, respectively. For both coagulants, their removal rates increased up to their optimum values as dosages increased. At dosages beyond the optimum, their removal rates decreased because of overdosing that caused the coagulation to destabilize, which in turn reduced the removal rates [12].

Influence of pH Value on Coagulation using Ferric Chloride and Chitosan. Studying the effect of $\mathrm{pH}$ on coagulation and flocculation is essential in determining the optimum $\mathrm{pH}$ for removal. A pH range of 4 to 9 was selected for the experiment. $\mathrm{FeCl}_{3}$ and chitosan were kept constant at their optimum dosages of 3600 and $60 \mathrm{mg} / \mathrm{L}$, respectively. The effects of $\mathrm{pH}$ on color and turbidity removal using $\mathrm{FeCl}_{3}$ and chitosan are shown in Fig. 3. The removal of color and turbidity using $\mathrm{FeCl}_{3}$ increased when $\mathrm{pH}$ increased from 4 to 9. The highest percentage of color and turbidity removal (95.54\% and $97.78 \%$, respectively) was achieved at a $\mathrm{pH}$ of 6 . As $\mathrm{pH}$ increased from acidic to basic, color and turbidity removal decreased. Therefore, a $\mathrm{pH}$ of 6 is the optimum for $\mathrm{FeCl}_{3} . \mathrm{pH}$ is responsible for controlling the hydrolysis species in the coagulation process. A series of soluble hydrolysis species form with the addition of a metal salt coagulant. These species can be either positively charged or negatively charged depending on the $\mathrm{pH}$ value of the sample used. A low $\mathrm{pH} \vee(<6)$ produces positively charged species, whereas a high $\mathrm{pH}$ produces negatively charged species. Positively charged hydrolysis species can penetrate and destabilize colloidal particles; this mechanism is known as the charge neutralization mechanism [13]. The $\mathrm{pH}$ of chitosan ( $\mathrm{pH}$ of 6 ) is lower than that of $\mathrm{FeCl}_{3}$. In our experiment, color removal decreased as $\mathrm{pH}$ increased from 4 to 9 


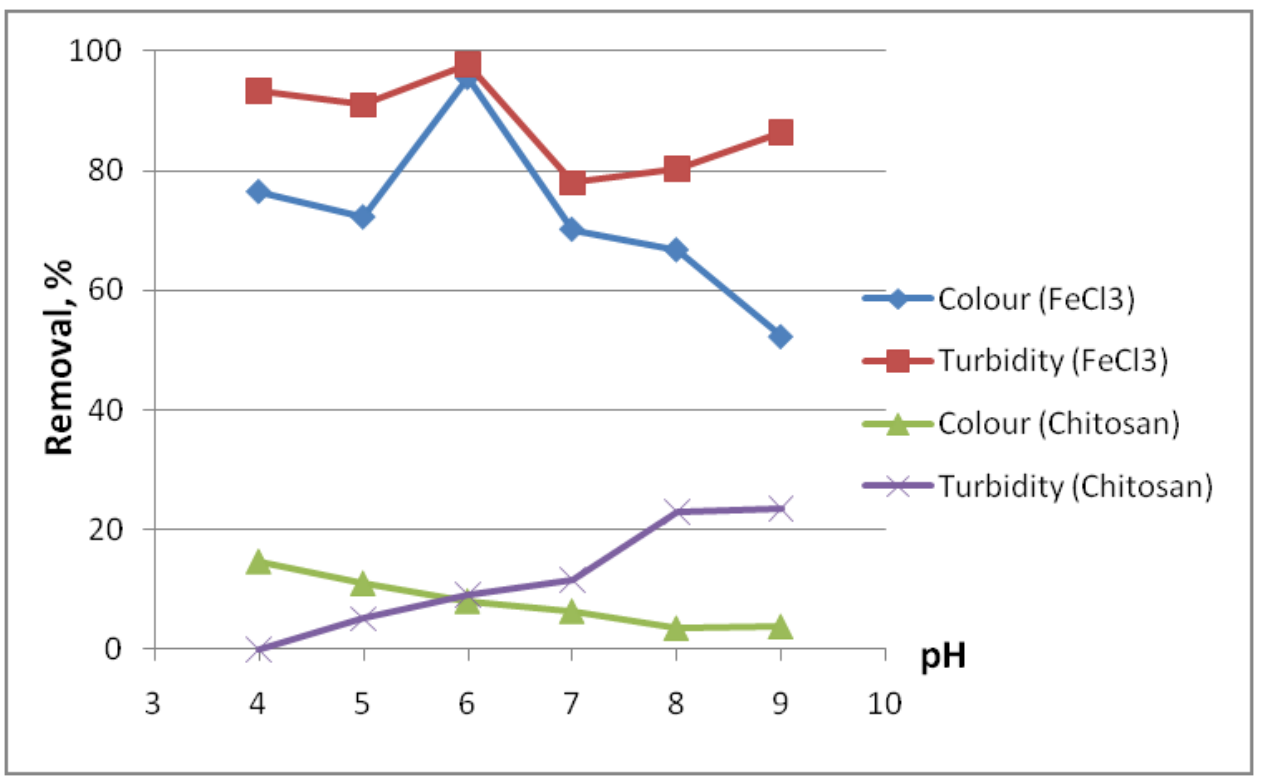

Fig. 3. Effects of $\mathrm{pH}$ Value on Color and Turbidity Removal using $\mathrm{FeCl}_{3}$ and Chitosan

. The highest color removal rate of $14.67 \%$ was reached at a $\mathrm{pH}$ of 4 using chitosan. Chitosan demonstrated a higher color removal rate than $\mathrm{FeCl}_{3}$ at a $\mathrm{pH}$ of 4 because at acidic conditions, chitosan becomes a positively charged coagulant as a result of the protonation of the amino group. Leachate, which has negative surface charges, tends to bind with the positively charged chitosan through hydrogen bonding [14]. Unlike that for color, turbidity removal increased when the $\mathrm{pH}$ level moved from acidic ( $\mathrm{pH}$ of 4$)$ to basic $(\mathrm{pH}$ of 9). Turbidity was not removed at a $\mathrm{pH}$ of 4. Turbidity removal $(23.52 \%)$ was observed at a $\mathrm{pH}$ of 9 .

\section{Conclusion}

$\mathrm{FeCl}_{3}$ achieved color and turbidity removal rates of $95.54 \%$ and $97.78 \%$, respectively, at an optimum $\mathrm{pH}$ of 6 and at an optimum dosage of $3600 \mathrm{mg} / \mathrm{L}$. Chitosan achieved low color and turbidity removal rates at $14.67 \%$ and $23.52 \%$, respectively. Therefore, $\mathrm{FeCl} 3$ removed colour and turbidity better than chitosan.

\section{Acknowledgments}

This work was supported by Universiti Sains Malaysia under RU-Team grant scheme RUT1001/PAWAM/854005. The authors also wish to acknowledge Majlis Perbandaran Taiping for their assistance during the sampling process.

\section{References}

[1] L. M. Rui, Z. Daud, A. A. A. Latif, Coagulation-flocculation in leachate treatment using combination of pac with cationic and anionic polymers, International Journal Of Engineering Research and Application (Ijera). 2 (2012) 1935-1940.

[2] L. M. Rui, Z. Daud, A. A. A. Latiff, Treatment of leachate by coagulation-flocculation using different coagualants and polymer: a review, International Journal On Advance Science Engineering Information Technology. 2 (2012) 1-4.

[3] S. Bhatia, Z. Othman, A. L. Ahmad, Coagulation-flocculation process for pome treatment using moringa oleifera seeds extract: optimization studies, Chemical Engineering. 133 (2007) 205212. 
[4] J. Bratby, Coagulation and flocculation in water and wastewater treatment, third ed., London, Iwa Publishing, United Kingdom, 2006.

[5] R. Sanghi, B. Bhattacharya, Comparative evaluation of natural polyelectrolytes psyllium and chitosan as coagulant aids for decolourization of dye solutions. 40 (2005) 97-101.

[6] M. A. A. Hassan, T. P. Li, Z. Z. Noor, Coagulation and flocculation treatment of wastewater in textile industry using chitosan. Journal of Chemical and Natural Resources Engineering. 4 (2009) 43-53.

[7] D. Zeng, J. Wu, J. F. Kennedy, Application of a chitosan flocculant to water treatment. Carbohydrate Polymers. 71 (2008) 135-139.

[8] N. A. Zainol, H. A. Aziz, M. S. Yusoff, Characterization of leachate from kuala sepetang and kulim landfills: a comparative study, Energy And Environment Research. 2 (2012) 45-52.

[9] N. S. M. Zin, H. A. Aziz, N. M. Adlan, A. Ariffin, M. S. Yusoff, I. Dahlan, A comparative study on the impact of dose on the removal of suspended solids, colour, chemical oxygen demand and ammonia, from partially stabilized leachate using ferric (iii) chloride and polyferric chloride through coagulation and flocculation processes, Advances in Mechanical Engineering. 3 (2013) 6668 .

[10] H. Patel, R. T. Vashi, Comparison of naturally prepared coagulants for removal of cod and color from textile wastewater, Global NEST Journal. 15 (2013) 522-528.

[11] S. M. Z. Mokhtar, M. A. Wahab, M. T. Selimin, N. C. Mohammad, Landfill leachate treatment by a coagulation-photocatalytic process, 2011 International Conference on Environment and Industrial Innovation. 12 (2011) 224-228.

[12] O. S. Amudaa, I. A. Amoo, Coagulation/flocculation process and sludge conditioning in beverage industrial wastewater treatment, Journal of Hazardous Materials. 141 (2007) 778-783.

[13] A. Agyun, T. Yilmaz, Improvement of coagulation-flocculation process for treatment of detergent wastewaters using coagulant aids, International Journal of Chemical and Environmental Engineering. 1 (2010) 97-101.

[14] N. Sakkayawong, P. Thiravetyan,W. Nakbanpote, Adsorption mechanism of synthetic reactive dye wastewater by chitosan, Journal Of Colloid And Interface Science. 286 (2005) 36-42. 